\title{
Digital Economics and Internet of Things: Visualization of Research Fronts
}

\author{
Anton D. NAZAROV ${ }^{1, a,{ }^{*}}$, Elena S. KULIKOVA ${ }^{2, b}$, and Maya I. L'VOVA ${ }^{3, c}$ \\ ${ }^{1}$ Ural State University of Economics, 620144, Russia, Ekaterinburg, 8 marta str., 62 \\ ${ }^{2}$ Ural State University of Economics, 620144, Russia, Ekaterinburg, 8 marta str., 62 \\ ${ }^{3}$ Ural State University of Economics, 620144, Russia, Ekaterinburg, 8 marta str., 62 \\ aantonnazarov2807@mail.ru, be.s.kulikova@indox.ru, cctig.usue@mail.ru \\ * Anton D. Nazarov
}

Keywords: Research fronts, Internet of things, Digital economy, Science metrics, Web of Science.

\begin{abstract}
The article deals with the transformation of digital economic processes in context of country's research activities development. Country needs to develop in current vector of science. We noted science metrics as one of the tools for finding the potential vector of science; we noted the science metrics, namely its mechanism for searching the current priority areas of scientific research fronts based on semantic analysis with selection of key words. A brief analysis and visualization of the research front of "Internet of things" is presented using the intelligent tool Essential Science Indicators, developed on the Web of Science platform. The author compares the significance of publications abroad with publications of Russian scientists, noting positive dynamics in terms of increasing the percentage of cited documents. The article also gives recommendations for the necessity of searching for research fronts on the basis of Russian Science Citation Index.
\end{abstract}

\section{Introduction}

Recently, information technologies have initiated new types of economic processes, the main tool for formation of which are digital technologies. Famous scientists such as M. Porat, D. Bell, F. Weber, D. Wada, K. Erro are considering the fundamental trends in transition to digital economy, noting the prevailing position of information technology and the importance of information as the main production resource along with finances and energy. [1,2]

In their scientific articles, scientists define a new economy as an "Internet economy" and related network processes, they highlight importance of information technologies and computer networks as the main competitive basis of an enterprise in any sphere.

One of the key areas of the digital economy is the Internet of things. The concept of the "Internet of Things" (IoT) originated from the Radio Frequency IDentification (RFID) systems proposed by the Massachusetts Institute of Technology (MIT) in 1999.

In 2005, the International Telecommunication Union (ITU) defined the IoT concept in its annual report as introducing mobile short-range transceivers into a wide range of additional gadgets and everyday items, new forms of cooperation and communication between people and people, people and things, as well as between the things itselves. Therefore, real-time interaction is available at any time all around the globe. IoT is considered the most important opportunity for transformation and development in the network information industry since invention of computer, Internet and mobile communications. In recent years, many countries have implemented plans for development of IoT and structure of relevant technologies and industries. [3]

With the support of advanced technologies such as cloud computing and IoT, cloud production breaks down the bottleneck of advanced production and becomes a new production paradigm. It turns production resources and production capabilities into production services that can be managed in an intelligent and unified way to ensure the complete exchange and dissemination of productive resources and opportunities. Cloud manufacturing can provide reliable, high-quality and affordable production services upon request for the entire production lifecycle. Among the main works in this 
key research, more than 70\% are researchers from the USA and China. Between these countries there is a high level of cooperation in the field of digital economy, in particular the research front of IoT. Recently, a number of countries, such as the United Kingdom, Sweden, Thailand, New Zealand, Poland and Canada have also become involved in active research and development of IoT in scientific sphere. [4,5]

\section{Material and Methods}

The methods of research are an analytical, legal statistical and theoretical-empirical method.

Consider the keyword "Internet things" from the point of view of science metric data, namely, by searching for research fronts.

The goal of science metrics as a science is to give an objective picture of scientific direction development, to evaluate its relevance and potential. The mechanism for studying the choice of scientific research vector was called "research fronts". [6]

Research Fronts are pools of highly cited publications made in the last 10 years in their subject areas, clustered on the basis of semantic analysis with selection of keywords. Such analysis makes it possible to reveal the intellectual structure of science and connections between various fields of research. Research fronts serve to determine the current priority areas of scientific researches, which attracts attention of scientific community. [7,8]

To visualize this technology, we use the Essential Science Indicators tool, developed on the Web of Science platform, which, with the help of scientific metrics, allows us to form priority areas of scientific activity.

\section{Results and Discussions}

Consider the example of "research front" using Essential Science Indicators tool.

The first column called "Research Fronts" shows a keyword pool selected by semantic analysis. Further, the indicator "Highly Cited Papers = 2" reflects the number of highly cited publications based on these keywords, and the "Main Year $=2012.5$ " indicator is the average year of publications in this direction. In other words, it answers question of relevance of the study (Fig. 1).

\section{Research Fronts}

THINGS (IOT); INTERNET; THINGS; VISION; FUTURE DIRECTIONS

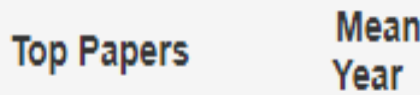

2012.5

Fig. 1 - Example of the research front

With the help of this tool, it is possible to find key directions for the development of economy and science of the whole country. According to figure 2, the research front of "Internet of things" contains two highly cited publications:

The first one is "Internet of things: a vision, architectural elements, and future directions" and other is "Internet of things: vision, applications and research challenges" [9]. These publications in 2012 and 2013 described the need to move to smart technologies, in particular "Internet of things", described the structure, functions, advantages and disadvantages of this technology. In particular, D. Mirandi and D. Sikari described "Internet of things" as a key word for covering various aspects related to the expansion of Internet into physical sphere through the large-scale deployment of spatially-distributed devices with integrated identification, probing and possibility of triggering. Internet of things implies a future in which digital and physical objects can be linked through relevant information and communication technologies to create a completely new class of applications and services [10]. 
1 INTERNET OF THINGS (IOT): A VISION, ARCHITECTURAL ELEMENTS, AND FUTURE DIRECTIONS

Times Cited: $\mathbf{5 2 5}$

By: GUBBI, J; BUYYA, R; MARUSIC, S; et.al

Research Front Source: FUTURE GENER COMPUT SYST

29 (7): 1645-1660 SEP 2013

Research Fields: COMPUTER SCIENCE

2 INTERNET OF THINGS: VISION, APPLICATIONS AND RESEARCH CHALLENGES

By: MIORANDI, D; SICARI, S; DE PELLEGRINI, F; et.al

Fig. 2 - Highly cited publications about IoT

Considering the research front of IoT in dynamics (Fig. 3) - it can be noted that for all indicators the main peak accounted for 2012-2016. Geography of the main researchers is divided between three countries: the USA, China and Canada.

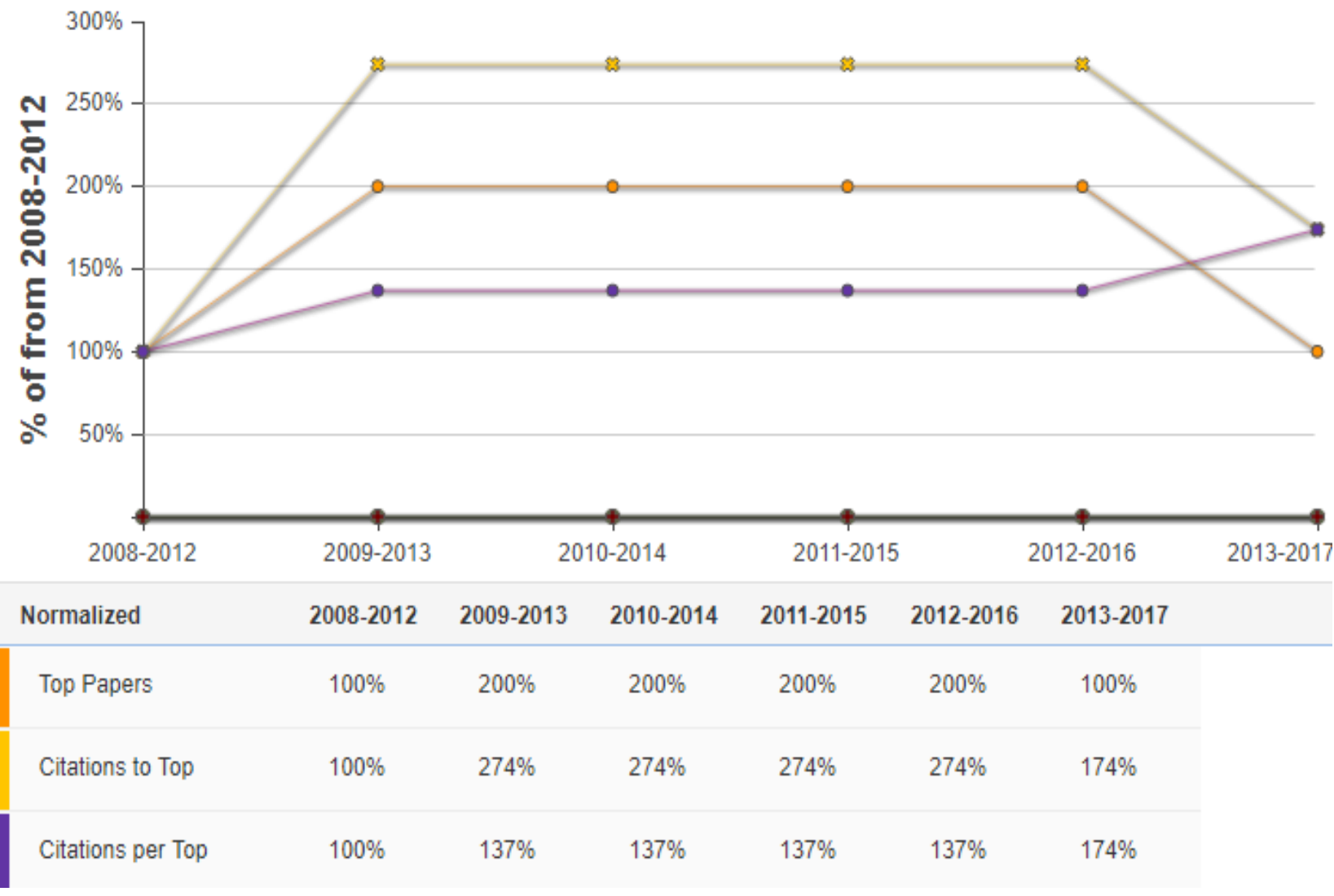

Fig. 3 - Dynamics of the research front of IoT

Scientific publications about IoT made by Russian scientists are not included in the pool of highly cited publications. Considering publications about "Internet things" in terms of the number of citations and the number of publications (Fig. 4) - you can see that Russian scientists have small indicators; for comparison, USA has 2,481 documents in the Web of Science database plus 15,307 citations and the Russian Federation has a lot fewer. However, based on the "\% Docs Cited" indicator, we can note positive dynamics of quoting our scientists in foreign databases. 


\begin{tabular}{|l|ccccc|}
\hline Name & Rank & $\begin{array}{c}\text { Web of } \\
\text { Science } \\
\text { Documents }\end{array}$ & $\begin{array}{c}\text { Category } \\
\text { Normalized } \\
\text { Citation Impact }\end{array}$ & $\begin{array}{c}\text { Times } \\
\text { Cited }\end{array}$ & $\begin{array}{c}\% \text { Docs } \\
\text { Cited }\end{array}$ \\
\hline$\square$ - USA & 1 & 2,481 & 2.53 & 15,307 & $42.48 \%$ \\
\hline$\square$ - CHINA MAINLAND & 2 & 3,832 & 1.38 & 10,833 & $32.2 \%$ \\
\hline$\square$ - CANADA & 3 & 449 & 2.42 & 1,609 & $43.88 \%$ \\
\hline$\square$ - RUSSIA & 4 & 166 & 3.31 & 293 & $36.75 \%$ \\
\hline
\end{tabular}

Fig. 4 - Comparison of science metric indicators of countries in context of IoT

\section{Conclusion}

In general, it should be noted that formation of a development strategy and support of scientific researches using research fronts is one of the primary tasks for development of economic researches of Russian science in the modern measurement. The implementation of this mechanism for strategic alternatives to Russian science is possible based on Russian Science Citation Index using intelligent data analysis.

\section{References}

[1] Gubbi, J., Buyya, R., Palaniswami, M. Internet of Things (IoT): A vision, architectural elements, and future directions. Future generation computer systems-the international journal of escience (2013). Vol. 29. No. 7, p. 1645. https://doi.org/10.1016/j.future.2013.01.010

[2] Miorandi D., Sicari S., Pellegrini F., Chlamtac I. Internet of things: Vision, applications and research challenges (2013). Ad Hoc Networks. Vol 10. № 7, p. 1497. https://doi.org/10.1016/j.adhoc.2012.02.016

[3] Kosten, J. Scientometrics (2016) 108: 457. https://doi.org/10.1007/s11192-016-1904-7

[4] Research Fronts 2016. (2016) Clarivate Analytics, Chinese Academy of Sciences. - p. 7th

[5] Andieva E.Yu., Filchakova V.D. Digital economy of the future, industry 4.0. Applied Mathematics and Fundamental Informatics. №12. p.7-11.

[6] Blaginin V.A., Matveeva A.I. Research Fronts: A Strategic Imperative for the Development of Russian Science. Moscow economic journal. 2016. № 4. p. 54.

[7] Blaginin V.A., Nazarov A.D. Modern bibliometric indicators as the foundation for assessing the state of science in Russia. In the collection: Social Innovation - 2015. p. 126-128.

[8] Evstigneev V.A. Scientometric research in computer science [Electronic resource] Access mode: http://www.computer-museum.ru/books/n_collection/investigat.htm

[9] Kasyanov P.E. Scientometrics in the anti-crisis management of scientific research [Electronic resource]. Access mode: elar.urfu.ru/bitstream/10995/43145/1/UrFU_conference_November_2016_ kasyanov.pdf

[10] Strelets I.A. Network economy / I.A. Sagittarius. - Moscow: Eksmo, 2006. - 208 p. 